DOI: http://dx.doi.org/10.30684/etj.36.1B.3

\section{Sihama I. Salih \\ Department of Materials Engineering, University of Technology, Baghdad, Iraq. Sihama_salih@yahoo.com}

\section{Wleed B. Salih}

Department of Physics University of Anbar, Anbar, Iraq.

\section{Mustafa S. Mohammed}

Department of Physics, University of Anbar, Anbar, Iraq.

Received on: 28/02/2017 Accepted on: 20/07/2017

\title{
Preparation and Investigation of Flexural Strength and Impact Strength for Nano Hybrid Composite Materials of the Tri- Polymeric Blend used in Structural Applications
}

Abstract-Current work is aimed to preparation the nanocomposites laminates of low density and good durability to use in structural applications. So, in this paper, the preparation and compare of some mechanical properties of two groups of tri-polymer blends composites consisting of $((93 \%$ unsaturated polyester resin (UP)+(5\%PMMA) (Poly methyl methacrylate) $+2 \% N R$ (Natural Rubber)) as the matrix materials. Added the reinforce materials ( silica $\left(\mathrm{SiO}_{2}\right)$ and zirconia $\left(\mathrm{ZrO}_{2}\right)$ nanoparticles) individually, with different volume fraction of $(0,0.5,1,1.5 \%)$ to the ternary polymer blends according to the following formula:- [((100-X) $(93 \% \mathrm{UP})+2 \% \mathrm{NR}+5 \% \mathrm{PMMA}):\left(\mathrm{X} \% \mathrm{SiO}_{2}\right.$ or $\left.\left.\mathrm{X} \% \mathrm{ZrO}_{2}\right)\right]$ The first group is composed of matrix material reinforced with zirconia $\left(\mathrm{ZrO}_{2}\right)$ nanoparticles with average diameter of nanoparticles (56.88nm) and the second group is composed of matrix material reinforced with silica $\left(\mathrm{SiO}_{2}\right)$ nanoparticles with average diameter of nanoparticles (24.59nm). Then used as a matrix material for the preparation of hybrid laminar composites materials, reinforcement with one and two layers of woven carbon fibers The research included the study of the influence of volume fraction of nanoparticles on some of mechanical and physical properties like flexural strength, flexural modulus impact strength, and impact fracture toughness, in addition to test infrared spectroscopy (FTIR) and all of these tests were carried out at laboratory temperature. Search results have shown that the values of (flexural modulus and impact strength and fracture toughness) increases with the increase of the nanoparticles ratios in polymer blend nano composite of prepared samples. While flexural strength value decreases with the increase in the volume fraction of nanoparticles in polymer blend nano composite. The fracture energy of the of hybrid laminar composites is higher than those containing only the nanoparticles powders. Morphology test by scanning electron microscope indicates that a good adhesion or interfacial interactions between the Nano powders particles, carbon fibers and components of ternary polymer blend. Which results in higher the carbon fibers efficiency factor, and hence higher mechanical strength. So, the hybrid laminar nano composites, which appear high flexural modulus and impact strength and fracture toughness, can be foreseen to provide valuable contribution to high performance structural applications.

Keywords- PMMA, Unsaturated Polyester ' Natural Rubber ‘ hybrid Nano Composite nano-silica, nano-zirconia, flexural strength.

How to cite this article: S.I. Salih, W.B. Salih and M.S. Mohammed, "Preparation and Investigation of Flexural Strength and Impact Strength for Nano Hybrid Composite Materials of the Tri-Polymeric Blend used in Structural Applications," Engineering and Technology Journal, Vol.36, Part B, No. 1pp. 12-24, 2018.

\section{Introduction}

Now a day's the composites are very widely uses and could be found everywhere. Polymers and polymer based are now being used to replace metal parts in many applications in our modern-day world, due to their relatively low costs and ease of processing, superior thermal, mechanical, and electrical properties. Depending on the chemical compositions and curing kinetics. However, polymers exhibit poor damage tolerance, low mechanical strength and stiffness relative to other engineering materials such as metals [1]. Therefore, their utilization as construction materials in industrial applications has been restricted to some extent. For that reason, various different methods including use of relevant chemical stabilizers and reinforcement constituents or blending of different types of polymershave been conducted to tailor mechanical 
and physical properties of polymers [2]. The most commonly utilized method to improve the performance of polymers is to turn them into polymer blend composite structures, through the use more than one mechanism, significant property improvements are currently made possible by (i) mixing the different polymeric material (ii) using resins, curing agents and co-monomers with new backbone chemistries, which provide networks with reduced moisture absorption, (iii) modification of the thermoset resins with thermoplastic polymer, and (iv) incorporating tough thermoset or thermoplastic in the form of interpenetrating network systems. The most successful strategies concerning the toughening of unsaturated polyester resins involve the incorporation of dispersed elastomeric and thermoplastic phases into the resin matrix, which results in a multiphase polymeric system [3]. (v) and then by using reinforcing materials with high strength. Polymeric composites have advantages over metal due to their lightweight, specific strength, high modulus, good fracture and fatigue properties as well as good corrosion resistance, and low-temperature processing. It is possible to vary their mechanical properties ranging from extreme flexibility to high strength and hardness, and physical properties such as adhesive strength, chemical resistance, heat resistance and electrical resistance. Thermosetting have been considered as the most promising candidate matrix polymers, so, have increased the urgent need to be used in many civilian and military applications, such as some of the aircraft parts, structures parts of structures industry land and marine vehicles and other [4,5]. At this stage, nanotechnology opens up a new perspective to shape new generations of composite structures. Nanoparticles possess unique mechanical and physical properties, which make them one of the most promising fillers to develop the future composite materials. Further, nanotechnology intends to reveal the size-related effects of nano particles to design innovative products with novel properties and functions. Therefore, nanocomposites, which are encompassed under nanotechnology, have aroused great scientific and industrial attention during the last years. As recent examples, using oil palm ash as a filler to form composites through the investigation of the effect of different contents of filler on the properties of oil palm ash filled unsaturated polyester (UP/OPA) composites. The tensile and flexural mechanical properties of UP/OPA composites were improved in modulus by increasing the filler content. Thermal stability of the composites increased as the OPA filler content was increased, which was a logical consequence because of the high thermal stability of the silica compound of the OPA filler compared with that of the UP matrix [6].

The effect of different weight percentages of carbon black nanoparticles on mechanical properties of unsaturated polyester, the results showed that the highest value for the tensile stress, flexural modulus and impact strength and impact fracture toughness and flexural strength and maximum shear stress occurs occurred when the rate of 3\% of carbon black, while the elongation at break decreased with increased fracture weighted carbon black [7]. Whereas, the particulate snail shell reinforced unsaturated polyester composite, showed that the flexural strength of the composite with $20 \mathrm{wt} \%$ snail shell particulate reinforcement was greatly enhanced and the impact and hardness properties were greatly improved at $5 \mathrm{wt} \%$ filler loading [8]. Reinforcement of unsaturated polyester by (grapes and dates) particulates, it have an important role in the improvement of the mechanical properties, the results showed that the tensile strength, modulus of elasticity and hardness and thermal conductivity of filled unsaturated polyester increase with the increment of the percentage of grapes and dates particles, while impact resistance decreases [9]. Whereas when adding metal powders (copper and aluminum) unilaterally to the unsaturated polyester resins, lead to increase in the values of tensile strength, modulus of elasticity and hardness with increase the volumetric fraction of metals powder and reached a maximum value at $15 \%$ volume ratio for both types composites, whereas flexural strength, flexural modulus and fracture toughness reach to maximum value at $10 \%$ volume fraction for both types composites [10]. And recent research shows that the unsaturated polyester reinforced with nanoparticles Chinese, the bending and tensile strength of the unsaturated polyester decreased with increased Chinese clay content, while the compressive strength and hardness increased with increasing clay content in composite [11].

The aim of the current work: is an attempt to improve in some mechanical properties of the polymer blend Nano hybrid composites, through the preparation of hybrid laminar composites, by adding two types of nano powders particles (silica and zirconia) and woven carbon fibers in the ternary polymer blend (UP $+2 \% \mathrm{NR}+5 \%$ PMMA\% 93).

\section{Materials and Experimental Work}

\section{Materials}


Unsaturated polyester (UP) is one of thermally hardened polymeric materials, is in the form of a transparent viscous liquid at room temperature, it turns into solid state when adding Hardener (Methyl Ethyl Keton Peroxide) MEKP is on the transparent liquid is added by the form $(2 \mathrm{~g})$ to $(100 \mathrm{~g})$ of unsaturated polyester resin at room temperature, was obtained from (Bonyan Kala Chemie) Iranian origin. Natural rubber (NR); Natural rubber used in this study type RSS-4 as Grade Sheets was obtained from Horizon Company, is one of the flexible polymer that have the ability for expansion and contraction used as one of the polymer mixtures. Moreover, poly methyl methacrylate (PMMA) resin is one of the thermally plasticity polymeric materials type (Castavaria) manufactured by ((Vertex -Dental Company)), is one of the thermally plasticity polymeric materials. Reinforcement materials nanoparticles is composed from nano silica $\left(\mathrm{SiO}_{2}\right)$ was obtained from (Nanjing Nano technology) Chinese Company, with average particles diameter $((24.59 \mathrm{~nm})$ (Figure 1 (a)) and nano zirconia $\left(\mathrm{ZrO}_{2}\right)$ was obtained from (Hongwu Nanometer) Chinese company, with average diameter $(56.88 \mathrm{~nm})$ (Figure 1 (b)). Atomic force microscope (AFM) was used to determine the average diameter of nanoparticle as and distribution of nanoparticles, carbon fibres was used as woven mat have fibres angle direction $\left(0^{\circ} / 90^{\circ}\right)$, and was used in this research as an inner layer (1 and 2 layers), made by (E. I. DuPont De Nemours and Company. In this study, toluene is used as a solvent for the bulk (NR), small pieces of (NR) are immerged in toluene, and left for few days then a solution of (NR) is obtained. Poly (methyl meth acrylate) (PMMA) is powder /selfcure acrylic and (MMA) self-cure liquid was used.

\section{Samples Preparatio}

Ternary polymer blend was prepared from unsaturated polyester (UP), natural rubber (NR) and poly methyl methacrylate (PMMA) in fixed weight ratios (93\% UP + 2\% NR + 5\% PMMA) as a matrix material. In this study, toluene was used as a solvent for the bulk (NR), a small piece of (NR) are immerged in toluene, and left for few days to obtain a solution of (NR). Poly (methyl meth acrylate) (PMMA) is powder /self-cure acrylic with (MMA) self-cure liquid was used. Hand lay-out technique was used to prepare the nano composite materials, from ternary polymer blend as a matrix material, reinforced with two different nano powders ceramic which is zirconia $\left(\mathrm{ZrO}_{2}\right)$ nanoparticles and silica $\left(\mathrm{SiO}_{2}\right)$ nanoparticles, incorporated in the individually form, by different loading $(0,0.5,1$ and $1.5 \%)$ in terms of volume fraction according to the following formula: - $[(100-X)$ $(93 \% \mathrm{UP}+2 \% \mathrm{NR}+5 \% \mathrm{PMMA}):\left(\mathrm{X} \% \mathrm{ZrO}_{2}\right)$ or $\left.\left(\mathrm{X} \% \mathrm{SiO}_{2}\right)\right]$, all the prepared mixtures were done at room temperature, by using ultrasonic mixing device for this purpose, for at least half an hour to insurance riddance of pores. Then the liquid mixture was poured into the mold continuously and regularly to fill the mold to the desired level, and allowed to cure for $48 \mathrm{~h}$ at room temperature $\left(27^{\circ} \mathrm{C}\right)$. To complete processing all the specimens are placed in drying oven for two hours at $\left(55^{\circ} \mathrm{C}\right)$ temperature according to the manufacturer instructions, this process is important to complete the polymerization, to reduce the residual monomers and to remove the stresses generated by the manufacturing process.

\section{Tests samples}

The Fourier transformation Infrared spectrum (FTIR) test is performed according to (ASTM E1252) [12]. By using Fourier transform infrared spectrometer, model (TENSOR 27) made in Germany, by (Bruker Optics Company). Infrared spectrum was used within range of (400- 4000) $\mathrm{cm}-1$. The flexural test is performed according to (ASTM D790) [13]. Using a three-point test instrument, (model WDW $200 \mathrm{E}$ ), at room temperature $(23 \pm 2)^{\circ} \mathrm{C}$, and at across head speed (strain rate) of $(5 \mathrm{~mm} / \mathrm{min})$ and load was applied equal to $(5 \mathrm{KN})$. Impact test is performed at room temperature according to ASTM ISO 179 [14], Izod charpy tension impact test measurement test machines, XJU-22 Time group Inc.

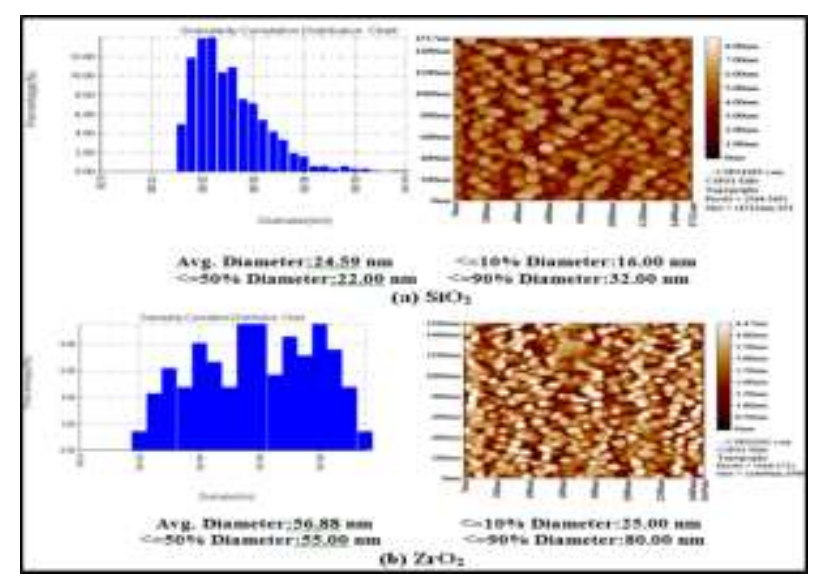

Figure 1: Atomic force microscope (AFM) to determine the average diameter of nanoparticle and nanoparticles distribution. Where (a): is $\mathrm{SiO}_{2}$ nanoparticles and (b): is $\mathrm{ZrO}_{2}$ nanoparticles. 


\section{3-Results and Discussion}

I. Fourier transforms infrared spectroscopy(FTIR)

Fourier transforms infrared spectroscopy (FTIR) was used, to fully characteristic band of tripolymer blend (93\% UP+2\%NR+5\%PMMA) and tri-polymer blend composite specimens. Figure (2) illustrated the infrared spectrum of unsaturated polyester. The presence of symmetric $(\mathrm{C}=\mathrm{O})$ stretching was confirmed by the presence of strong bend at $(1721.04) \mathrm{cm}^{-1}$, this band confirms the presence of $(\mathrm{C}=\mathrm{O})$ ester group and confirms the formation of unsaturated polyester [15]. Two aromatics, ring breathing bands a doublet at (1600. 7) $\mathrm{cm}^{-1}$ and an addition medium absorption bend peak at (1449.26) $\mathrm{cm}^{-1}$ can be attributed to $(\mathrm{C}-\mathrm{H})$ bending. Spectrum absorption bend at $1156.83 \mathrm{~cm}^{-}$ ${ }^{1}$ confirms the presence of $(\mathrm{C}-\mathrm{O}-\mathrm{C})$ of ester linkage [16]. Unsaturated in plane deformation at (1071.45) $\mathrm{cm}^{-1}$, a strong absorption band at (741.93) $\mathrm{cm}^{-1}$ and (700.22) $\mathrm{cm}^{-1}$ attributed to $(\mathrm{C}-\mathrm{H})$ out of plane bending deformation in benzene ring [16].

The infrared spectrum of ternary polymer blend (93\%UP+2\%NR+5\%PMMA) and ternary polymer blend reinforced with different ratio of $\left(\mathrm{ZrO}_{2}\right)$ nanoparticles $(0,0.5,1$ and $1.5 \%)$ as they are shown in Figure 2. All the characteristics vibration bands of unsaturated polyester (Figure 3) and of ternary polymer blend (93\%UP+2\%NR+5\%PMMA) (Figure 3) are presented in infrared spectrum of ternary polymer blend nano composites specimens,

The presence of $\mathrm{ZrO}_{2}$ particle in ternary polymer blend nano composites caused the weakening and finally the disappearance of the bands attributed to $(\mathrm{O}-\mathrm{Zr}-\mathrm{O})$ bands in $\left(\mathrm{ZrO}_{2}\right)$. Except the weak peak appear at (494.44) $\mathrm{cm}^{-1}$ region is due to the $\mathrm{Zr}-\mathrm{O}$ vibration, which confirm the formation of $\mathrm{ZrO}_{2}$ structure [17]. No new peaks or peak shifts were observed for the these group nano-composites specimens, except the sample reinforced with $1.5 \%$ ratio of $\left(\mathrm{ZrO}_{2}\right)$ nanoparticle, which shows the disappearance or decay peaks own to unsaturated polyester material, and that may be related to agglomerated $\left(\mathrm{ZrO}_{2}\right)$ nanoparticles, which are accumulation of isolated particles which are connected to each other and with constituents of composite material by attractive physical interactions forces, and this, may be done in a adversely effect on radiation absorption, and that may be caused in reflected the infrared radiation rather than absorbed by the components of material.

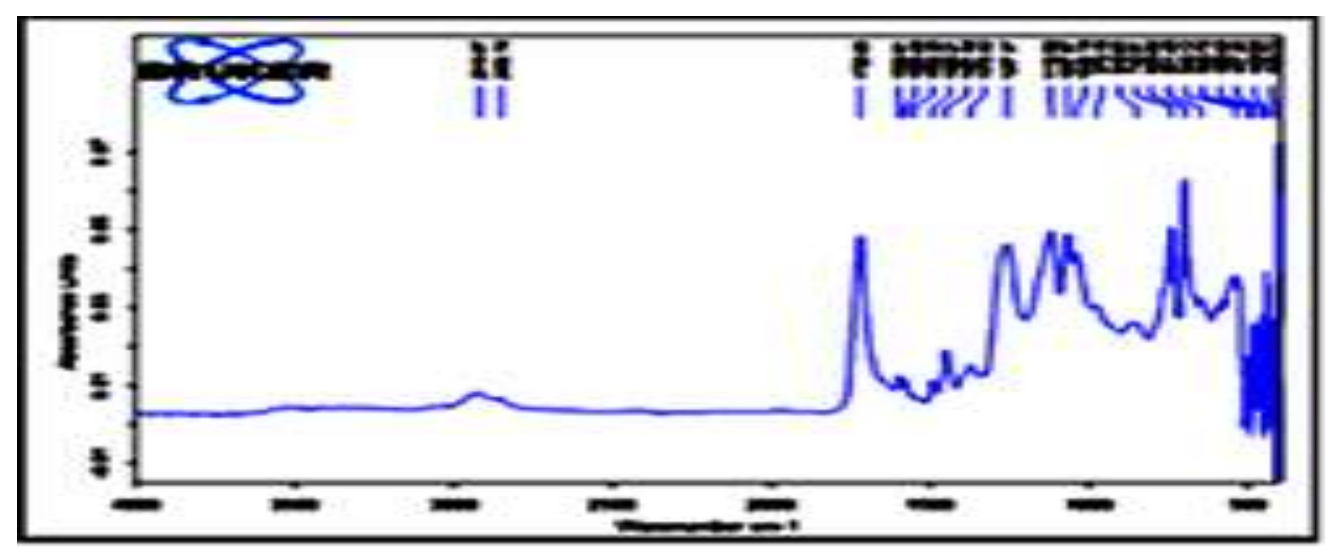

Figure 2: FTIR spectrum for neat unsaturated polyester material. 


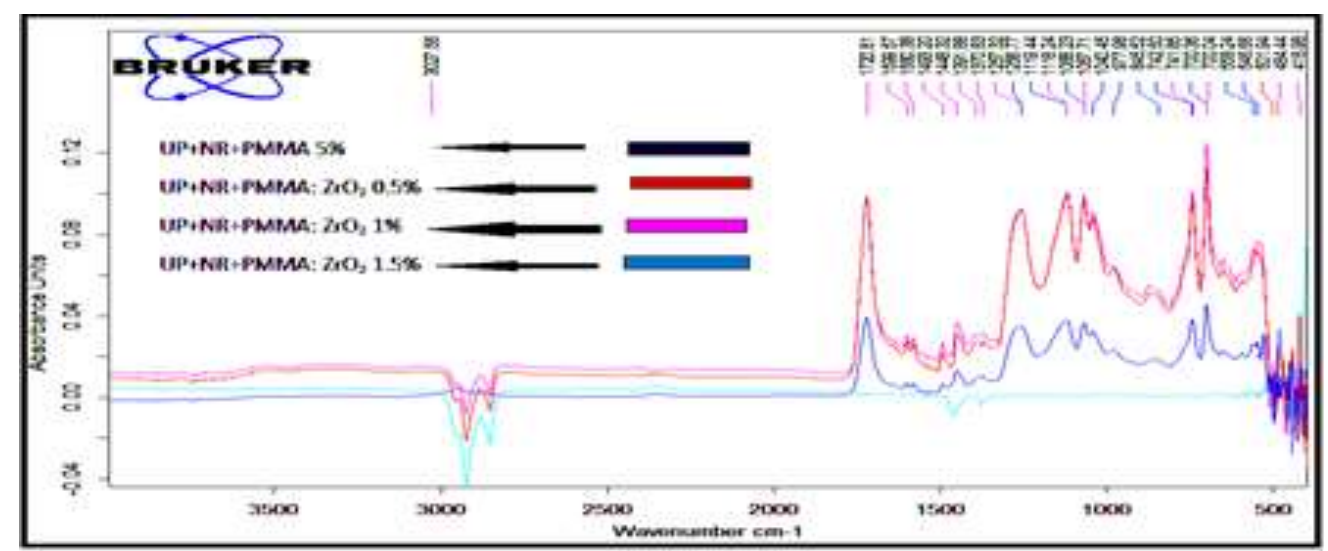

Figure 3: FTIR spectrum for ternary polymer blend nanocomposites as a function of $\mathrm{ZrO}_{2}$ nanoparticles content in composite samples.

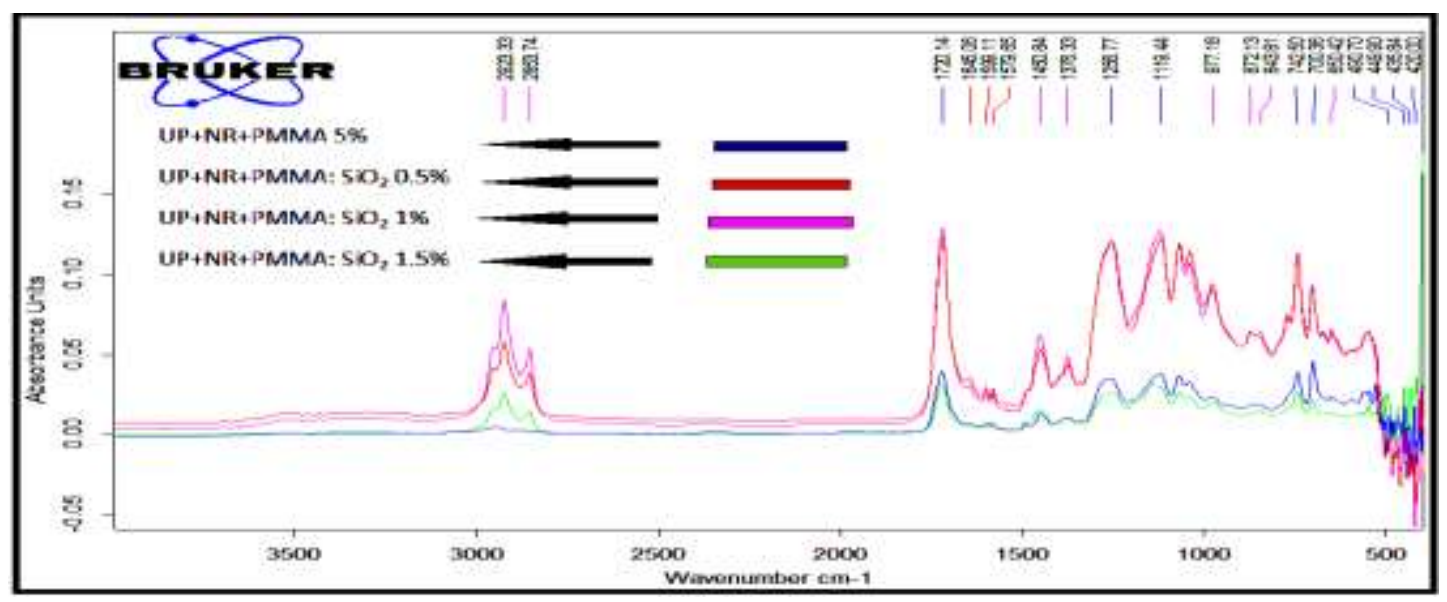

Figure 4: FTIR spectrum for ternary polymer blend nanocomposites as a function of $\mathrm{SiO}_{2}$ content in composite samples.

The FTIR spectra of ternary polymer blend (93\%UP+2\%NR+5\%PMMA) and polymer blend nanocomposites specimens, reinforced with different ratio of $\mathrm{SiO}_{2}$ nanoparticles $(0,0.5,1$ and $1.5 \%$ ) are shown in Figure 4. From this figure it was observed that, all the characteristics vibration bands of unsaturated polyester (Figure 2) and of ternary polymer blend $(93 \% \mathrm{UP}+2 \% \mathrm{NR}+5 \% \mathrm{PMMA})$ are presented in (FTIR) spectra of ternary polymer blend nano composite samples. The presence of $\mathrm{SiO}_{2}$ particle in ternary polymer blend nanocomposites caused the weakening and finally the disappearance of the bands attributed to $(\mathrm{O}-\mathrm{Si}-\mathrm{O})$ bands in $\left(\mathrm{SiO}_{2}\right)$. Except the peak appear at (449.9) $\mathrm{cm}^{-1}$ attributed to ( $\mathrm{Si}-\mathrm{O})$ bands in $\left(\mathrm{SiO}_{2}\right)$ [18]. As well as, it can be seen from the infrared spectrum of these group composite specimens (figure (4)), no other new peak or peak shifts were observed for the ternary polymer blend nanocomposite specimens with the addition $\left(\mathrm{SiO}_{2}\right)$ nanoparticles, this is due to find physical bond and absence any cross linking in these specimens. There is a clear increase in peaks intensity for all of characteristic peak with increasing $\left(\mathrm{SiO}_{2}\right)$ ratio and it reaches a maximum at $\left(1 \% \mathrm{SiO}_{2}\right)$ and then peaks intensity decrease when $\left(\mathrm{SiO}_{2}\right)$ ratio reaches to $1.5 \%$ in polymer blend nano composite.

\section{Mechanical Tests Results}

\section{Bending Results Test}

The effect of the addition of zirconia and silica nanoparticles in solitary form in ternary polymers blends (93\%UP+2\%NR+5\%PMMA) on the flexural properties (flexural strength and flexural modulus) is shown in the Figures 5 ( $a$ and $b$ ) respectively. As compared with the ternary polymer blend, it was found from Figure 5 (a) that, the addition of zirconia and silica nanoparticles led to decreasing the values of flexural strength of this ternary polymer blend, each of these nanoparticle, it may be have functional own with direction of applied stress. The reasons behind such a behavior are that the agglomeration and stick of the zirconium oxide nano powder together, and so do 
silica nanoparticles, especially with the high concentrations ratio $(0.5-1.5 \%)$, these powders plays an important role in stress concentrators. So, when the flexural was applied on the specimen, the intensity of the stress concentration increases dramatically near the agglomerated nanoparticles and making the de bonding between PMMA and nanoparticles and this cause cracks propagate faster inside the composite materials so that, the fracture occurs immediately, this result is in a good agreement with other workers results by Arezou et al. [19]. As well as, the reinforcement of nanoparticle, may be worked to create some flaws inside the matrix material, especially in areas containing clusters of nanoparticles, this may be as the result to the distribution of nanoparticles was not homogeneous in inside a matrix material, and this, may be serve as the centres for stresses concentration, which causing the low flexural strength values for nano-composites samples, as this behaviour is linked to the bad wettability between the nanoparticles (zirconia or silica) and ternary polymeric blend components, especially with the high concentrations ratio causing weakness interconnections actual between the components of composite material and thus lead to a reduction in the stresses needed for occurs the failures in the specimens [20].

Furthermore, these nanoparticles may be not work as an adjective barrier in front of developing cracks through the composite materials, that do not work on the obstruction of cracks growth and this will lead to change the shape and direction of the cracks, leading to its transformation into a minor cracks group causing the decrease in flexural strength values [21. Figure (5b) represents the relationship between the flexural modulus of nanocomposites and the content of volume fraction of (zirconia or silica) nanoparticles in composite materials, it can be observed from this figure, that the values of flexural modulus was increasing with the increased in the volume fraction content of nanoparticles inside the matrix material for the ternary polymer blend, and it is possible that due to the addition of the nanoparticles (zirconia or silica) to the ternary polymer blend may work to increase the physical bonding of polymeric chains, and this reduces in the chains distortion, which could happen within the limits of elasticity, and that it will leads to increase in the flexural Modulus of the nano-composite specimens of the prepared materials, as compared to the matrix material of ternary polymeric blend. As well as, it can be shown from Figure ( $5 \mathrm{a}$ and $\mathrm{b}$ ), that the flexural strength and flexural modulus for the composites samples, which reinforce with silica nanoparticle, are higher than those values for the composite samples reinforced with the zirconia nanoparticle. Such behaviour is related to the incorporation of the nanoparticles powders into the ternary polymeric blend. that the nanoparticles powders tend to form a soft or hard agglomerates depend on the nature of each of these particles, moreover, the increased in the flexural properties it may be connected with the nature of silica nanoparticles which have smaller in the nano-sizes $(24.59 \mathrm{~nm})$ and this lead increases the contact area and thus increase the flexural properties of the nano composites samples, as compared with their counterparts of nano composites reinforced with zirconia nano powder, which owns the largest in the nano-sizes $(56.88 \mathrm{~nm})$ [22].

Figures 6 ( $a$ and $b$ ) and 7 (a and b) shows the effect of adding a single layer or two layers of carbon fibres to flexural strength and flexural modulus respectively, for nano composites laminates materials, (ternary polymer blend $+1 \%$ zirconia + (1-2) layers of carbon fibre), and other reinforced $1 \%$ silica nanoparticles (ternary polymer blend + $1 \%$ silica $+(1-2)$ layers of carbon fibre). From Figure $6(\mathrm{a}$ and $\mathrm{b}$ ) noted that the addition of one layer or two layers of carbon fibres increased the flexural strength of the two types of nano composites laminates materials, as well as it was observed that the flexural strength of nano composites laminates materials, reinforced by $1 \%$ zirconia nanoparticles and with one or two layers of carbon fibres have higher values of flexural strength as compared with the flexural strength of samples reinforced by $1 \%$ silica nanoparticles and with one or two layers of carbon fibres. The highest values of the flexural strength reached to (300MPa) for sample of the polymer blend reinforced with $1 \%$ zirconia and two layers of carbon fibres, and the lower values reached to (148 $\mathrm{MPa}$ ) for sample of the polymer blend reinforced with $1 \%$ silica and one layer of carbon fibre, The reason for the increase in flexural strength due to the nature of the cohesion force and increase the strength of bonding between the carbon fibres and constituents of nano composites materials, as a result of increasing overlap mechanical between them, and that the increase wettability the fibre texture with fusible of a matrix material will increase the strength of adhesion in binding sites at the contact surfaces, and thus improve the extent of tangles or interference by mechanical linkage of matrix material because the mechanical linkage depends on the nature of the fibres surface [23]. The retention of fibres strength and durability during and after forming, and that will be confer a higher elasticity coefficient and this will increase the quality and efficiency of the prepared nano composites more especially when reinforcing with 
carbon fibres [24]. From Figure 7(a and b) noted that the addition of one layer or two layers of carbon fibres increased the values of flexural modulus of nanocomposites laminates materials which reinforced with $1 \%$ zirconia nano powders, while flexural modulus values decreased when laminar nano composites materials, reinforced with $1 \%$ silica nano powders. As well as it was observed through the Figures 7 ( $a$ and $b$ ) that the flexural modulus of laminar nano composites materials, reinforced by $1 \%$ zirconia nanoparticles and with one or two layers of carbon fibres have higher values of flexural modulus as

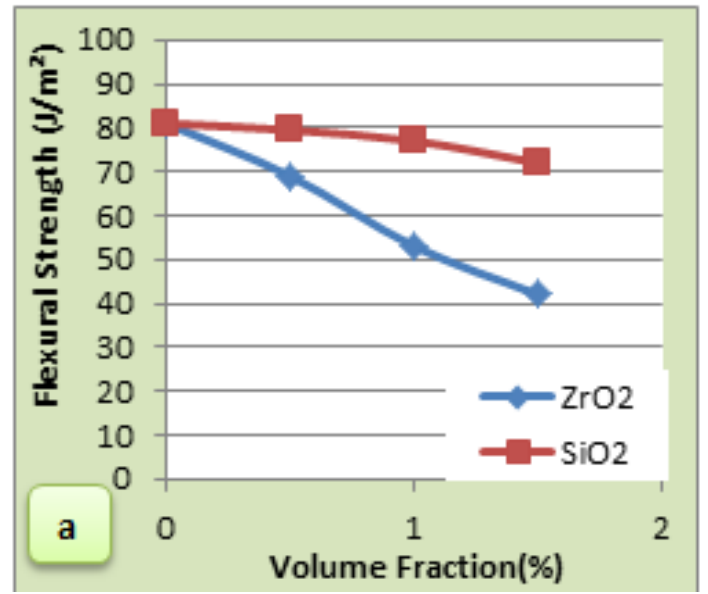

compared with the flexural modulus of their counterparts of the samples reinforced by $1 \%$ silica nanoparticles and with one or two layers of carbon fibres, moreover, can be seen that, the higher values reached to ( $8.44 \mathrm{GPa})$ for sample of the polymer blend reinforced with $1 \%$ zirconia and two layers of carbon fibres, and the lower values reached to (3.69 GPa) for sample of the polymer blend reinforced with $1 \%$ silica and one layer of carbon fibres, due to the same reasons mentioned in the paragraph above in flexural strength.

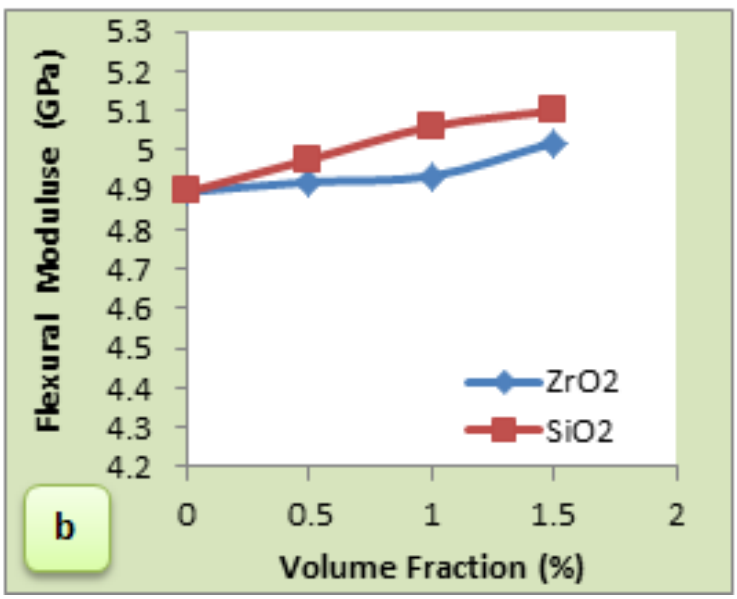

Figure 5: Flexural strength (a) and Flexural modulus (b) for ternary polymer blend nano-composite samples as a function of (silica or zirconia) nanoparticles content in composites.
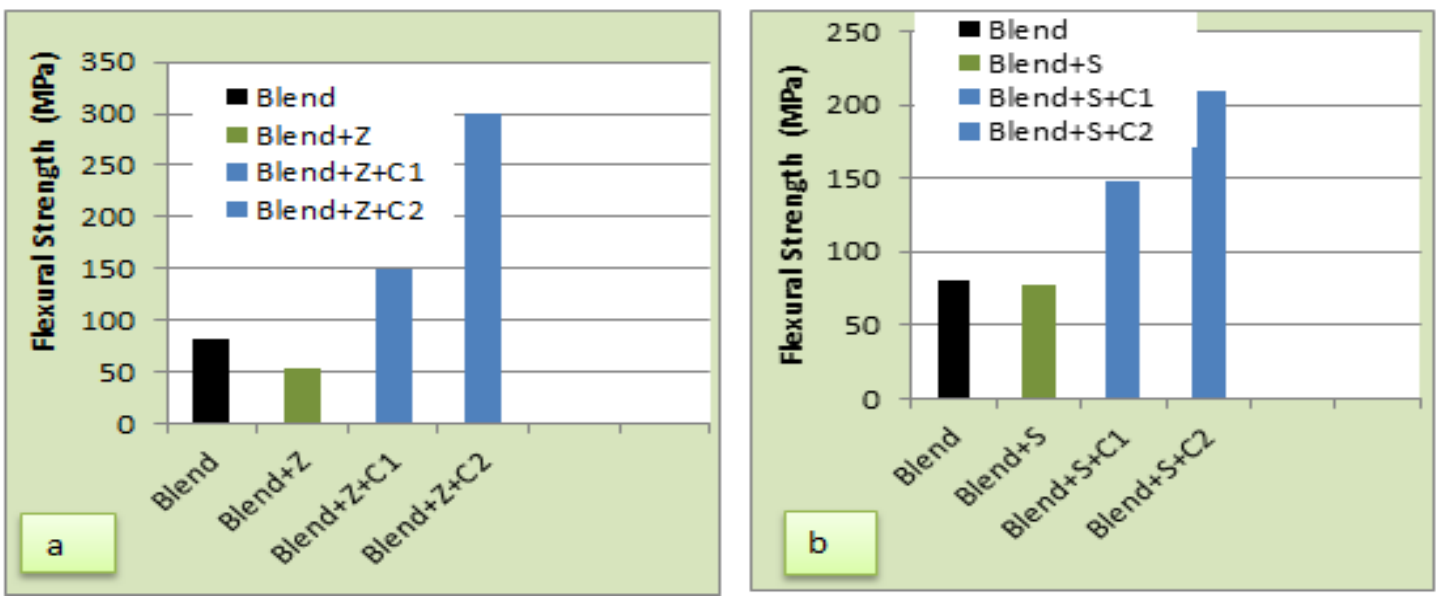

Figure 6: Flexural strength for laminar nano composites materials where: -

(a): $-\left[\left((93 \% \mathrm{UP}+2 \% \mathrm{NR}+5 \% \mathrm{PMMA}): 1 \% \mathrm{ZrO}_{2}\right)+((1\right.$ and 2 layers $\left.) \mathrm{CF})\right]$

(b):- $\left[\left((93 \% \mathrm{UP}+2 \% \mathrm{NR}+5 \% \mathrm{PMMA}): 1 \% \mathrm{SiO}_{2}\right)+((1\right.$ and 2 layers $\left.) \mathrm{CF})\right]$ 

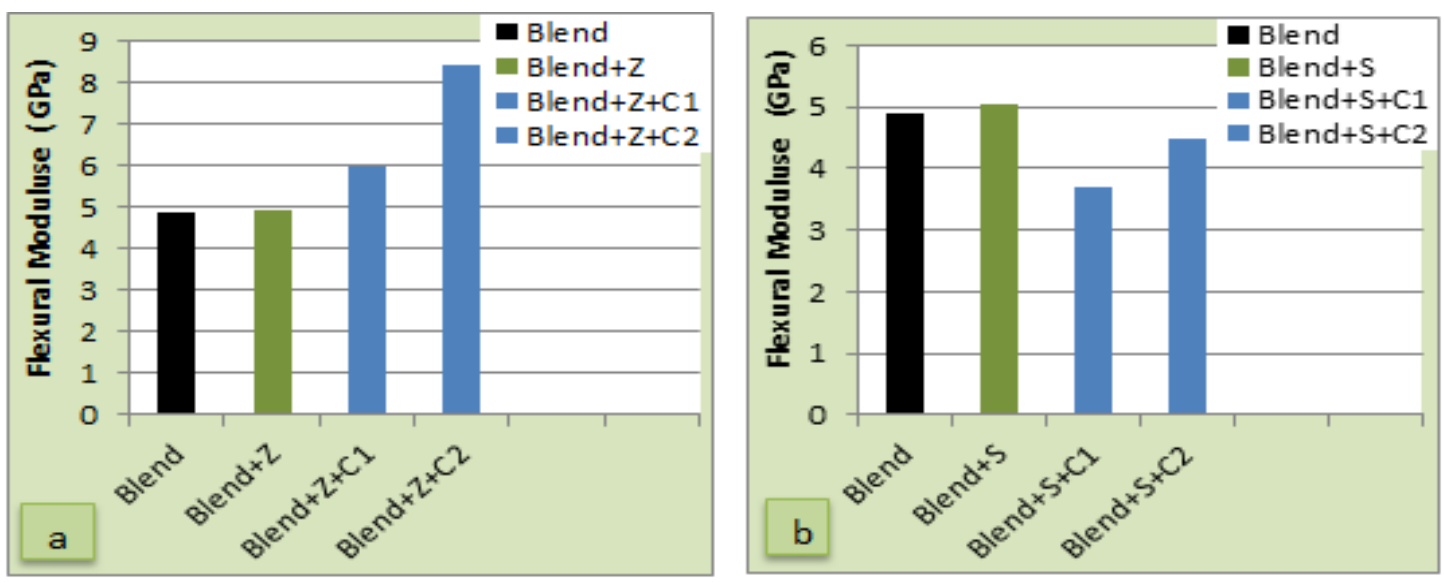

Figure 7: Flexural modulus for laminar nano composites materials where:(a):- [((93\% UP+2\% NR+5\% PMMA $): 1 \% \mathrm{ZrO2})+((1$ and 2 layers $) \mathrm{CF})]$ (b):- [((93\%UP+2\% NR+5\% PMMA):1\%SiO2) + ((1 and 2 layers) CF $)]$

\section{Impact Test Results}

Figure 8 ( $\mathrm{a}$ and $\mathrm{b}$ ) shows the effect of adding (zirconia or silica) nanoparticles (as reinforcement materials) on the impact strength and fracture toughness respectively for ternary polymeric blend nano-composite samples. Through these figures, was noticed that the Impact strength and fracture toughness values increases with increased of nanoparticles content in the nano composite material, This is due to the contribution of reinforcement materials to raising the Impact strength and fracture toughness of the matrix material, and this is due to the raise the shear strength, as a result of the formation of strong bonds between the components of the ternary polymer blend and the nanoparticles powders that was added to nano composite, in addition to the increase in the wettability between the nanoparticles (zirconia or silica) and the components of ternary polymer blend, which have a key role in improves the bonding strength between the components of composites materialsand thus lead to increased energy needed to break the sample. and it is expected that the nanoparticles working to obstruction the progress of the fracture and this is depend on the bonding strength of the interface between the reinforcement materials and components of the matrix material, and that will be lead to change the movement direction of the fracture through the interface of the particle If there is no failure is occurs in the particles, all of these causes contributed to increase the Impact strength and fracture toughness for nano composites samples. Furthermore, from Figure 8 ( $a$ and $b$ ), it can be shown that the Impact strength and fracture toughness for the nano composites samples reinforced with silica nanoparticle have the higher values as compared with their counterparts of other group of nano composites samples reinforced by zirconia nanoparticle, and this may be related with the nature of nanoparticle silica, which has small nanoparticle sizes $(24.59 \mathrm{~nm})$, and this may be make good wettability between the silica nanoparticles and the components of ternary polymer blend $[20,22]$.
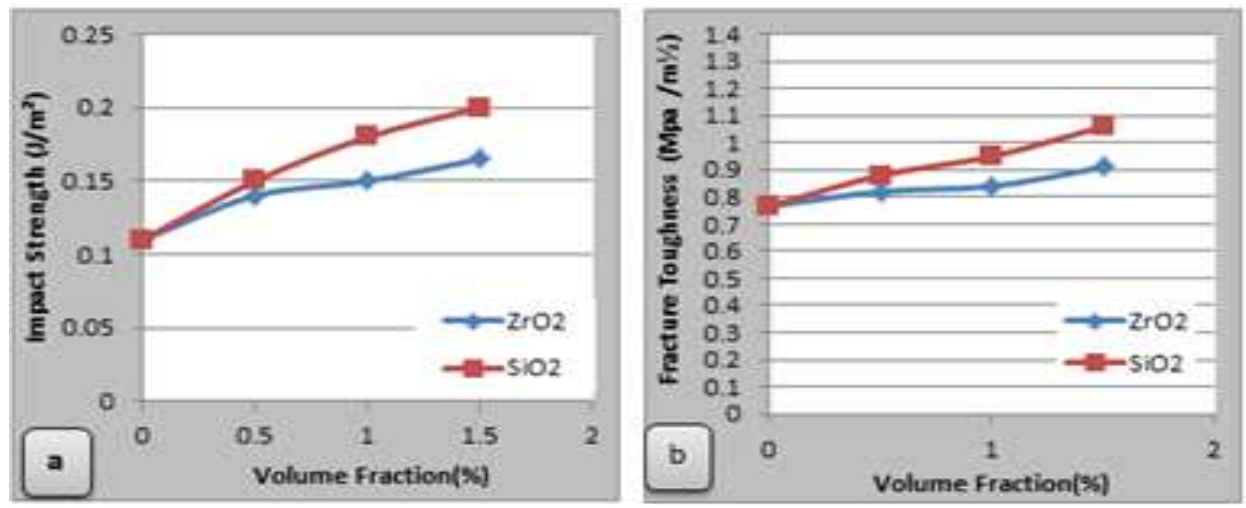

Figure 8: Impact strength (a) and Fracture toughness (b) for ternary polymer blend nano-composite samples as a function of (silica or zirconia) nanoparticles content in composite. 

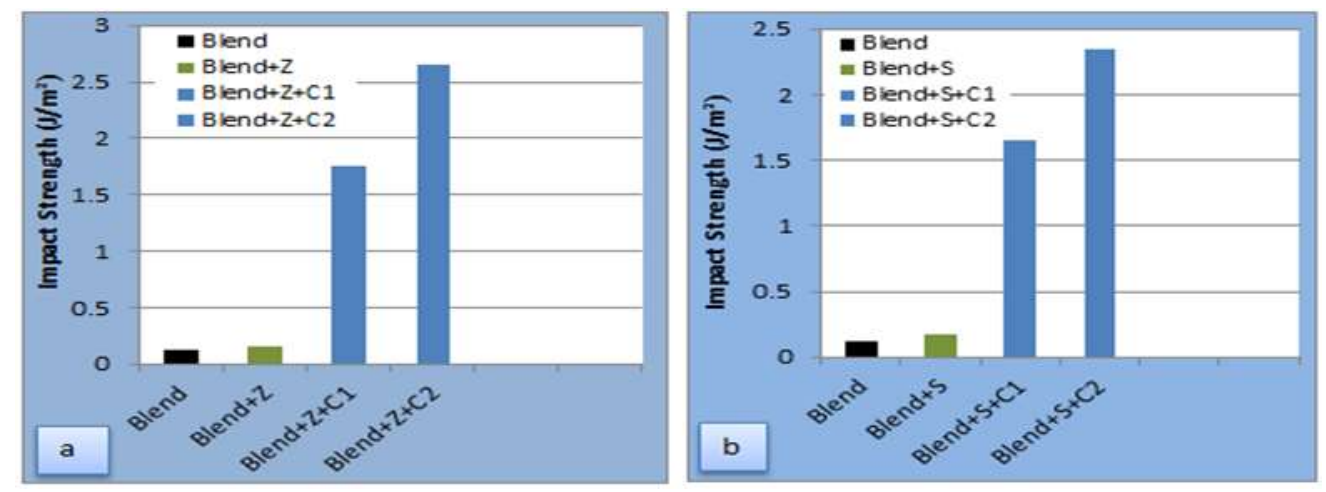

Figure 9: impact strength for laminar nano composites materials where:(a): - [((93\% UP+2\% NR+5\%PMMA):1\% $\left.\mathrm{ZrO}_{2}\right)+((1$ and 2 layers $\left.) \mathrm{CF})\right]$ (b): - [((93\% UP+2\% NR+5\% PMMA $\left.): 1 \% \mathrm{SiO}_{2}\right)+((1$ and 2 layers $\left.) \mathrm{CF})\right]$
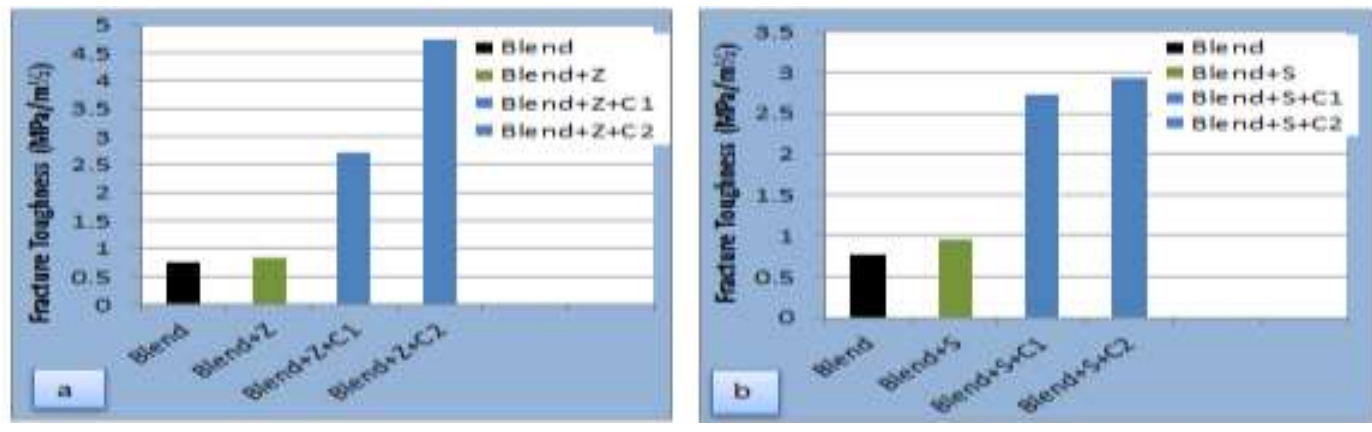

Figure 10: Fracture toughness for laminar nano composites materials where:(a): $-\left[\left((93 \% \mathrm{UP}+2 \% \mathrm{NR}+5 \% \mathrm{PMMA}): 1 \% \mathrm{ZrO}_{2}\right)+((1\right.$ and 2 layers $\left.) \mathrm{CF})\right]$ (b): - [((93\% UP+2\% NR+5\%PMMA):1\% $\left.\mathrm{SiO}_{2}\right)+((1$ and 2 layers $\left.) \mathrm{CF})\right]$

Figures $9(\mathrm{a}$ and $\mathrm{b})$ and $10(\mathrm{a}$ and $\mathrm{b})$ shows the effect of adding a single layer or two layers of carbon fibres to impact strength and fracture toughness respectively, for laminar nano composites materials, (ternary polymer blend + $1 \%$ zirconia $+(1-2)$ layers of carbon fibre), and other reinforced $1 \%$ silica nanoparticles (ternary polymer blend $+1 \%$ silica $+(1-2)$ layers of carbon fibre). From these figures, noted that the addition of one layer or two layers of carbon fibres increased the impact strength and fracture toughness values in high ratio for both types of laminar nano composites materials. Moreover, it was observed from the Figures 9 and 10 ( $a$ and $b$ ), that the impact strength and fracture toughness values of laminar nano composites materials, reinforced with $1 \%$ zirconia nanoparticles and with one or two layers of carbon fibres slightly higher as compared with the impact strength and fracture toughness values of their counterparts for the samples reinforced by $1 \%$ silica nanoparticles and with one or two layers of carbon fibres, and the higher values of impact strength and fracture toughness reached to $\left(2.65 \mathrm{~J} / \mathrm{m}^{2}\right)$ and $(4.72$ $\left.\mathrm{MPa} / \mathrm{m}^{1 / 2}\right)$ respectively, for samples of the polymer blend reinforced with $1 \%$ zirconia and two layers of carbon fibres, and the lower values reached to $\left(1.65 \mathrm{~J} / \mathrm{m}^{2}\right)$ and $\left(2.71 \mathrm{MPa} / \mathrm{m}^{1 / 2}\right)$ respectively for samples of the polymer blend reinforced with $1 \%$ silica and one layer of carbon fibres. The reason for the high increase in impact strength values when adding carbon fibres as compared with the values of nano composites samples, it is related with carbon fibres properties which have high durability and impact strength, as well as to the durability of the mechanical linkage between the fibres and the matrix material, and this needs extra power to break or pull out the fibres from the prepared nano composites samples, in addition to the foregoing also can attributed the reason for the high increase to the pattern direction of applied force which is parallel to fibres direction, and this leads to withstand high stresses and therefore to absorb the bulk of the energy required to break [25].

\section{Morphological analysis.}

In order to correlate the mechanical properties of the ternary polymer blend nano-composite samples as a function of (silica or zirconia) nanoparticles content in composites with the fracture surface morphology, the Scanning electron microscopy SEM micrographs were done to the flexural tested fractured surface for thete 
rnary polymer blend and polymer blend nanocomposite samples with different composition at same magnification (1000x) were recorded in Figures 11 and 12 respectively. The morphology of immiscible polymer blends depends on the processing conditions, nature components, ratios, and component melt viscosities. In most heterogeneous systems, a morphology whereby one phase is distributed in another phase is observed. So, the fracture surface of both systems shown in Figures 11 and 12 (a, b, c and d) exhibited a heterogeneous morphology, both systems appear to have a co-continuous morphology and as a result it was difficult to identify the individual polymers in this blend and composites. The SEM images (figure 11) of the fractured surface of the ternary polymer blend with unsaturated polyester resin as a matrix clearly showed two distinct phases a continuous binary blend (unsaturated polyester - PMMA) and a little amount of dispersed rubber phase, which were described by the arrows of a red colour. Rubber particles present will act as energy dissipating centre in the ternary polymer blends this result is a good agreement with other worker results [26, 27]. As well as from Figures (11 and 12) different phase morphologies it can be observed, depending on the composition of nano composites and chemical reaction in the ternary mixture.

as shown in Fig. 11, that crack propagated from the debonded interface due to the weaker interfacial adhesion between the components of ternary polymer blends, whereas from Fig. 12 it was observed better dispersion of $\mathrm{SiO}_{2}$ nano powders in ternary polymer blends matrix, It can be seen in the Fig. 12 ( $a, b$ and $c$ ) that less interfacial debonding occurred which indicates the improved interfacial adhesion. Thus, more energy is needed to break this interlink and start the fracture. As well as, morphology of connected globules was observed when add $1 \%$ and $1.5 \%$ of volume fraction of silica nanoparticle and $1 \%$ zirconia nanoparticle to polymer blend as its shows in Figure 12 ( $\mathrm{a}, \mathrm{b}$ and $\mathrm{C})$. Whereas add $1.5 \%$ volume fraction of zirconia nanoparticle lead to segregations and agglomeration of these nanoparticle in some regions of polymer blend composite as shown in Figure 12 (d). In addition, this is causing the deterioration of the mechanical properties of the prepared composite samples.

Photography SEM of the fracture surface morphology of laminar hybrid nano composites consisting of ternary polymer blend reinforced by $1 \%$ volume fraction of the silica nanoparticles and with a single layer of carbon fiber, is shown in Figure 13 ( $a$ and $b$ ) at different magnifications (1000X and 2500X). it was noticed through microscopic imaging SEM figure $13(a, b)$ of the fracture surface samples the emergence of some of the wreckage of the small fibers, which date back to the broken fibers when the failure is occurred in the sample, as well as, it was appearing to be the wreckage of fiber remained coated by a matrix material, even after the for failure, which were described by the arrows of a red colour. Moreover Figure 13 (b) shows a much smoother fracture surface, and that most of the carbon-fiber became part (embedded) of the a matrix material, the fibers were buried inside the polymer blend of a matrix material, which were described by the arrows of a blue colour, which shows get a good correlation between the components of nano composite material which seems to indicate better interfacial adhesion between carbon fibers materials and components of polymer blend nano composite materials.

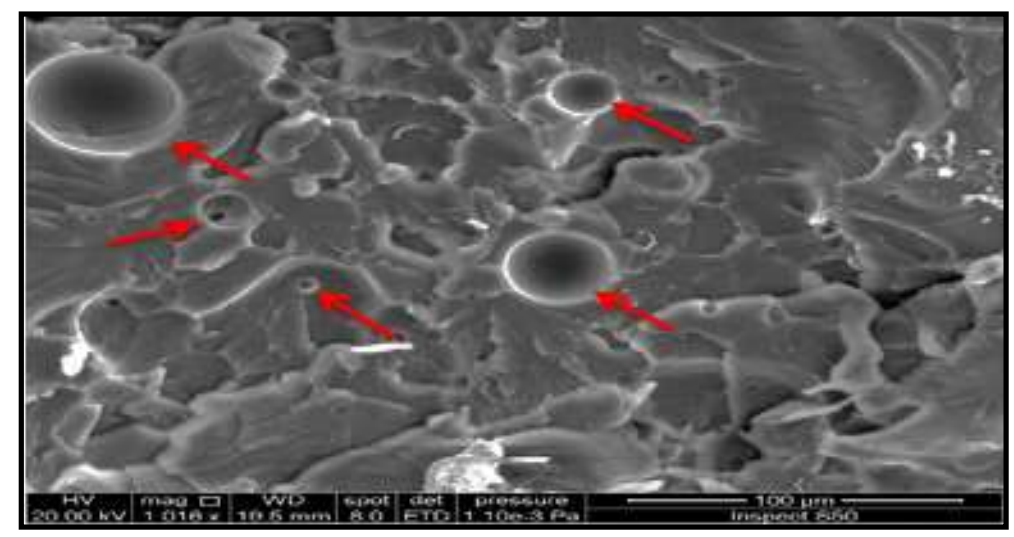

Figure 11: SEM image of fractured surface of ternary polymer blend $(93 \% \mathrm{UP}+2 \% \mathrm{NR}+5 \% \mathrm{PMMA})$ at magnification 1000X. 


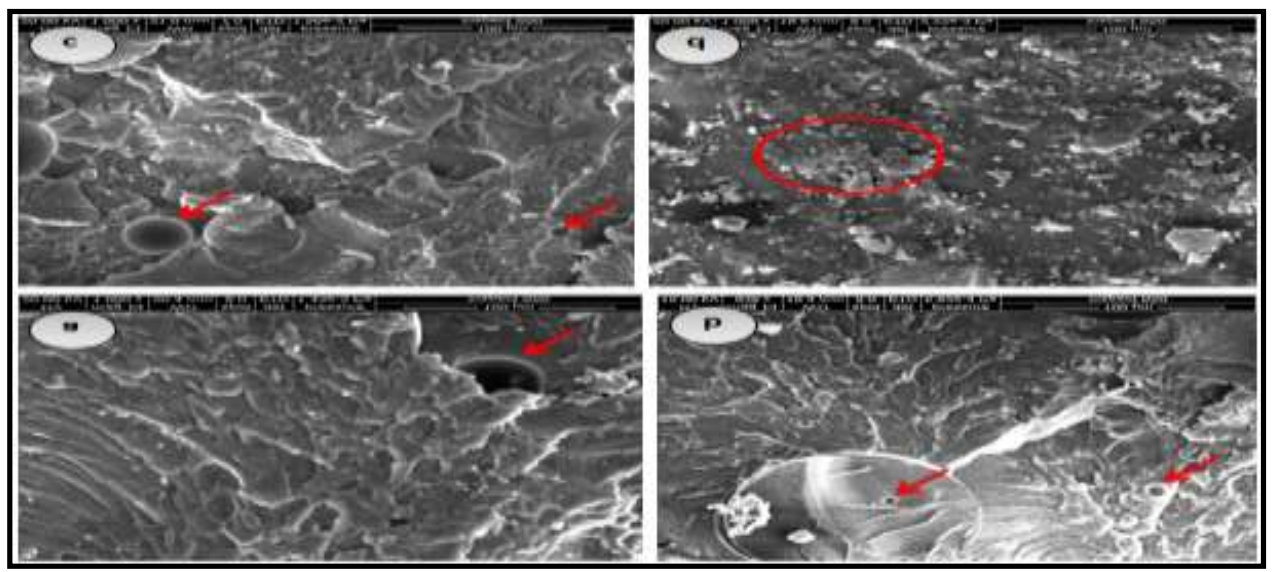

Figure12 SEM micrographs of the fracture surface morphology of hybrid nano-composite as a function of nanoparticles content in composite, $(93 \% \mathrm{UP}+2 \% \mathrm{NR}+5 \% \mathrm{PMMA}): \mathrm{x} \% \mathrm{SiO} 2$ or $\mathrm{x} \% \mathrm{ZrO2})$. Where (a):

$1 \% \mathrm{SiO} 2,(\mathrm{~b}): 1.5 \% \mathrm{SiO} 2,(\mathrm{c}): 1 \% \mathrm{ZrO} 2$ and $(\mathrm{d}): 1.5 \% \mathrm{ZrO} 2$, at the same magnification $1000 \mathrm{X}$.
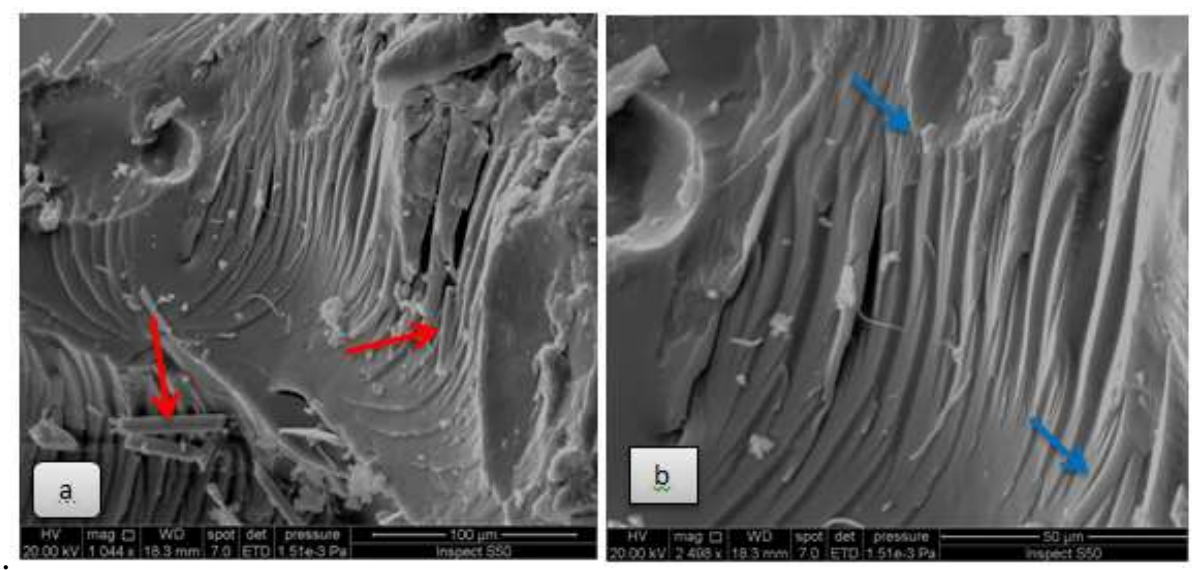

Figure 13: SEM micrographs of the fracture surface morphology of laminar hybrid nano-composite reinforcement with silica nano powders and woven carbon fibers. At different magnification (1000X and 2500X).

\section{Conclusions}

Polymers blend composites are becoming more attractive for structural applications due to reasons: their superior corrosion resistance, excellent thermo-mechanical properties, and high strength-to-weight ratio. However, the problem with this composite system is that the interface between the reinforced material and a matrix component (ternary polymer blend) is inherently weak. This leads to poor mechanical properties deteriorating the properties. This investigation is an attempt to address these deficiencies by inclusion of powders nanoparticles in polymer blend composites. So, two different types of nanoparticles powder $(\mathrm{SiO} 2$ and $\mathrm{ZrO} 2)$, it was added individually to ternary polymer blend.

So that, according to the tests of some mechanical properties for these nano composites. It was conclusion that, the addition of powders nanoparticles, led to the improvement of some mechanical. Increased the values of flexural modulus to $(30.8 \%)$ and $(17.7 \%)$ when added
(1.5\% silica) and (1.5\% zirconia) respectively to ternary polymer blend material. Whereas the impact strength and fraction toughness values were increased to $(81.8 \%)$ and $(50 \%)$ ratio respectively with adding ( $1.5 \%$ silica), while addition of (1.5\% zirconia) increase these values to $(50 \%)$ and $(31.8 \%)$ respectively as compared to ternary polymer blend samples. So, it was selected two samples from nano composites materials, which are (93\% UP+2\% NR+5\%PMMA): $1 \% \mathrm{SiO} 2)$ and (93\% UP+2\% NR+5\%PMMA): $1 \% \mathrm{ZrO} 2)$.

Then these selected samples were reinforced with one layer or two layers woven carbon fibers. Therefore, it was concluded that the fracture energy of the of hybrid laminar composites is higher than those containing only the nanoparticles powders.

Morphology test by scanning electron microscope indicates that a good adhesion or interfacial interactions between the Nano powders particles, carbon fibers and components of ternary polymer blend. Which results in higher the carbon fibers efficiency factor, and hence higher mechanical 
strength. So, the hybrid laminar nano composites, which appear high flexural modulus and impact strength and fracture toughness, can be foreseen to provide valuable contribution to high performance structural applications.

\section{Nowledgment}

We would like to express our thanks to the Department of Materials Engineering/University of Technology /Iraq, for helping us in carrying out this research, through the fabrication of research samples and in carrying out experimental tests for this work.

\section{References}

[1] M. Tanoglu and A.T Seyhan. "Investigating the effects of a polyester performing binder on the mechanical and ballistic performance of E-glass fiber reinforced polyester composites," International Journal of Adhesion and Adhesives 23, 1-8, 2003.

[2] S.N.E. Naqvi, S. Naveed, S.H. Javaid, N. Ramzan "Enhancing the Chemical and Mechanical Properties of Upr," Journal of Quality and Technology Management Volume X, Issue I, PP 1 - 15, 2014.

[3] S.I. Salih, K.M. Shabeeb and Q.A. Hamad, "Studying Mechanical Properties for Polymer Matrix Composite Material Reinforced by Fibers and Particles," Eng. \& Tech. Journal Vol. 28 No. 4, 81-95, 2010.

[4] H. Baley, "Mechanical Properties of Composites Based on Low Styrene Emission Polyester Resins for Marine Application," Y. Perrot, Peter Davies, Journal of Applied Composite Materials, Vol. 13, No. 1, 1-22, 2006.

[5] J.G. Jones and J. Summerscales, "Marine applications of advanced fiber reinforced composites," Woodhead Publishing, 74-76, 2015.

[6] M.S. Ibrahim, S.M. Sapuan and A.A. Faieza, "Mechanical and Thermal Properties of Composites from Unsaturated Polyester Filled with Oil Palm Ash," Journal of Mechanical Engineering and Sciences (JMES), Volume 2, 133-147, 2012.

[7] A.H. Nassir "Studying the Effect of Nano Carbon Black on Mechanical Properties of Unsaturated Polyester Resin,” The Iraqi Journal for Mechanical and Material Engineering, Vol. 13, No. 4, 2013.

[8] C.I. Madueke, B. Bolasodun, R. Umunakwe. "Mechanical Properties of Tere-Phthalic Unsaturated Polyester Resin Reinforced with Varying Weight Fractions of Particulate Snail Shell," Journal of Polymer and Textile Engineering (IOSR-JPTE), Volume 1, Issue 4, 39-44, 2014.

[9] S.H. Kamel. "Studying Some of The Mechanical Properties of Unsaturated Polyester Reinforced by ReCycled Natural Materials," Al-Qadisiyah Journal for Engineering Sciences, Vol. 8, No. 2, 137-146, 2015.
[10] S.I. Salih, S. Nayyef, A.H. Abd alsalam and A.M. Hasan, "Evaluation of Mechanical Properties of Polymer Composites Reinforced by different Metal Powders," Eng. \& Tech. Journal, Vol. 33, Part (B), No. 3, 1348-1360, 2015.

[11] N.L.N. Hilary, I.Z. Luna, A.M. Sarwaruddin, M.A. Gafur and R.A. Khan, "Preparation And Mechanical Characterization Of Polyester Resin/China Clay Nanocomposites," European Journal of Pure and Applied Chemistry Vol. 3, No. 1, ISSN 2398-1385, 4957, 2016.

[12] Annual Book of ASTM Standard, "Standard Practice for General Techniques for Obtaining Infrared Spectra for Qualitative Analysis," E 1252-98, 1-11, 2002.

[13] ASTM, D. 790-03, "Standard Test Methods for Flexural Properties of Unreinforced and Reinforced Plastics and Electrical Insulating Materials," ASTM International, West Conshohocken, PA, 2003.

[14] Annual Book of ISO Standard. "Standard Test Method for Unnotched Izod Impact Testing of Plastics," ISO-179, 1-2, 2006.

[15] K. Caba, P. Guerrero and M. Jose, M. Kenny, "Comparative Study by DSC and FTIR Techniques of an Unsaturated Polyester Resin Cured at Different Temperatures," Polymer International 45, 333-338, 1998.

[16] A.R. RAHMAT \& R.J. DAY "Curing Characteristics of Unsaturated Polyester/Aramid Reinforced Composite: Microwave VS. Thermal Energy," Jurnal Teknologi, 39, 83-96, 2003.

[17] A.K. Singh and U.T. Nakate "Microwave Synthesis, Characterization, and Photoluminescence Properties of Nanocrystalline Zirconia," Hindawi Publishing Corporation Scientific World Journal Volume, Article ID 349457, 7, 1-7, 2014.

[18] O.M. Sadek, S.M. Reda, R.K. Al-Bilali. "Preparation and Characterization of Silica and ClaySilica Core-Shell Nanoparticles Using Sol-Gel Method," Advances in Nanoparticles, 2, 165-175, 2013.

[19] A. Sezavar and S.A. Sajjadi, "A Study on the Effect of Nano Alumina Particles on Fracture Behavior of PMMA," Department of Materials Science and Engineering, Engineering Faculty, Ferdowsi University of Mashhad, No. 3, 94-102, 2015.

[20] S.I. Salih, J.K. Oleiwi and Q.A. Hamad, "Comparative Study the Flexural Properties and Impact Strength for PMMA Reinforced by Particles and Fibers for Prosthetic Complete Denture Base," The Iraqi Journal for Mechanical and Material Engineering, Vol. 15, No. 4, 289-307, 2015.

[21] A.A. Mohamed, and I.E. Mohamed, "Effect of Zirconium Oxide Nano Fillers Addition on the Flexural Strength, Fracture Toughness and Hardness of HeatPolymerized Acrylic Resin," World Journal of Nano Science and Engineering, Vol. 4, No. 2, 50-57, 2014.

[22] B.R. Varadharajan, W.N. P Hung, \& H.J. Sue, "Fatigue of Epoxy a-Zirconium Phosphate Nanocomposites," In Proceedings of the ASEE Gulph- 
Southwest Annual Conference Texas A\&M UniversityCorpus Christi, 2005.

[23] A.K. Singh and U.T. Nakate, "Microwave Synthesis, Characterization, and Photoluminescence Properties of Nanocrystalline Zirconia," Hindawi Publishing Corporation Scientific World Journal Volume, Article ID: 349457, 7, 1-7, 2014.

[24] B.S Puskar, T. Potran, M. Markovic, D. Pilic, B. Pavlicevic, J. and V. Kojic, "Modulus of Elasticity, Flexural Strength and Biocompatibility of Poly (methylmethacrylate) Resins with Low Addition of Nanosilica ," Journal of Dental Sciences, Vol. 4, Issue 1, 26-33, 2016.

[25] W.D. Callister, "Materials Science and Engineering an Introduction," 6th ed, John Wiely and Sons, Inc. New York, 2003.

[26] S.K. Tan, S. Ahmad, C H. Chia, A. Mamun and H.P. Heim "A Comparison Study of Liquid Natural Rubber (LNR) and Liquid Epoxidized Natural Rubber (LENR) as the Toughening Agent for Epoxy," American Journal of Materials Science, 3, 3, 55-61, 2013.

[27] F.L. Barcia, T.P. Amaral and B.G. Soares, "Synthesis and properties of epoxy resin modified with epoxy-terminated liquid polybutadiene," Polymer, Vol. 44, Issue 19, 5811-5819, 2003. 